\title{
Identificação de padrões de defeitos em redes de distribuição elétrica a partir de imagens térmicas.
}

\section{Aline R. da Silva*, Júlio C. Pereira, Rangel Arthur}

\section{Resumo}

A demanda pelo fornecimento de energia elétrica cresceu nos últimos anos e, por isso as empresas distribuidoras de energia elétrica necessitam de serviços de entrega com melhor qualidade. $O$ uso da termografia infravermelha como técnica preditiva associada ao uso de outras técnicas de processamento de imagens ajudam na identificação de defeitos em elementos que podem causar falhas elétricas, evitando-se assim interrupções de fornecimento de energia nas linhas de distribuição.

\section{Palavras-chave}

Inspeção termográfica, termografia infravermelha, linhas de distribuição.

\section{Introdução}

O processo de identificação do funcionamento irregular nas linhas de distribuição de energia elétrica pode ser feito por meio da análise e segmentação de imagens obtidas por câmeras termográficas. A medição de temperaturas ou observação de padrões diferenciais de distribuição de calor, a partir de raios infravermelhos emitidos pelo objeto que está sendo analisado, propicia a obtenção de informações relativas à condição operacional de um componente, equipamento ou processo, de tal forma que as anomalias que representam as descontinuidades possam ser reconhecidas. ${ }^{1}$

\section{Resultados e Discussão}

Com o auxílio das ferramentas de Sistemas de Visão In Sight Explorer 5.1.1 e FLIR Tools, foram feitas algumas segmentações em algumas imagens térmicas. Nesse processo, subdivide-se a imagem em regiões ou objetos afim de que sejam identificados certos erros e anomalias nos sistemas, sendo eles correlacionados a pontos de sobreaquecimento, curto-circuito, entre outros. Para isso foram estudadas e utilizadas diferentes técnicas de segmentação como por exemplo: Algoritmo Watershed, reconhecimento de padrões, detecção de borda e Thresholdings. Além disso, utilizou-se também o software Matlab para segmentar algumas imagens, as quais foram sendo armazenadas para futuras comparações.

Figura 1. Imagem térmica segmentada e com elementos de erros identificados

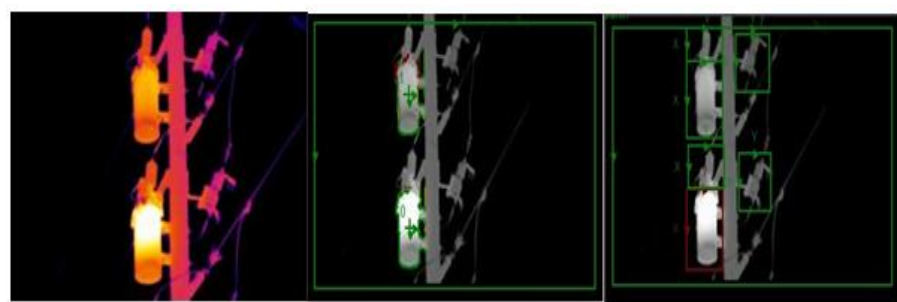

Tabela 1. Ações a serem tomadas em cada nível de temperatura $^{2}$

\begin{tabular}{|c|c|c|c|}
\hline Prioridade & $\begin{array}{c}\text { Escala da } \\
\text { temperatura } \\
\text { comparada a } \\
\text { components } \\
\text { similares } \\
\text { sob as } \\
\text { mesmas } \\
\text { condições } \\
\left({ }^{\circ} \text { C) }\right.\end{array}$ & $\begin{array}{l}\text { Diferença } \\
\text { quando } \\
\text { comparada a } \\
\text { temperature } \\
\text { do ambiente } \\
\left({ }^{\circ} \text { C) }\right.\end{array}$ & $\begin{array}{c}\text { Ação } \\
\text { recomendada }\end{array}$ \\
\hline $\mathbf{4}$ & $1-3$ & $1-10$ & $\begin{array}{l}\text { Possível } \\
\text { deficiência, } \\
\text { investigar }\end{array}$ \\
\hline $\mathbf{3}$ & $4-15$ & $11-20$ & $\begin{array}{l}\text { Provavelmente } \\
\text { indica deficiência, } \\
\text { reparar de possível }\end{array}$ \\
\hline $\mathbf{2}$ & - & $21-40$ & $\begin{array}{l}\text { Monitorar } \\
\text { medidas corretivas } \\
\text { serem realizadas }\end{array}$ \\
\hline 1 & $>15$ & $>40$ & $\begin{array}{l}\text { Maior discrepância; } \\
\text { reparo imediato }\end{array}$ \\
\hline
\end{tabular}

\section{Conclusões}

Após a segmentação das imagens utilizando-se das técnicas mencionadas, podem ser obtidos diversos parâmetros, os quais serão utilizados para identificação automática de erros e falhas nas linhas de distribuição.

\section{Agradecimentos}

Ao Conselho Nacional de Desenvolvimento Científico e Tecnológico (CNPq), pela concessão da bolsa de Iniciação Científica, ao meu orientador Prof. Dr. Rangel Arthur e ao Mestrando Júlio César Pereira pelo suporte e por terem me ensinado muito durante esse tempo.

${ }^{1}$ Snell, John e Stuart, Michael, Introduction to Thermography Principles. 2009, American Techical Publishers, Inc., Fluke Corporation, and the Snell Group.

${ }^{2}$ J. Snell, R.W. Spring, New approach to prioritizing anomalies found during thermographic electrical inspections, 2003, 108, 3335. 